\title{
MRS. DALLOWAY NO CINEMA: O FLUXO DE CONSCIÊNCIA
}

\author{
MRS. DALLOWAY: THE STREAM OF CONSCIOUNESS IN THE MOVIES
}

\author{
Rosana de Fátima Gelinski ${ }^{1}$
}

\begin{abstract}
RESUMO
Este artigo pretende analisar como a técnica literária chamada fluxo de consciência estrutura-se no filme As Horas, dirigido por Stephen Daldry, levando em consideração alguns aspectos da obra Mrs. Dalloway, de Virginia Woolf, que serve de inspiração para o livro As Horas, de Michael Cunningham, e também para o filme homônimo, bem como abordagens a respeito do tempo e do espaço em ambas as narrativas.
\end{abstract}

Palavras-chave: Cinema. Literatura. Tempo.

\begin{abstract}
This article aims at analyzing how the stream of consciousness literary technique is dealt with in the movie The Hours by Stephen Daldry, taking into account some aspects of Virginia Woolf's literary work Mrs. Dalloway, which inspired the book and the movie The Hours. It also analyzes different approaches to time and space in both narratives.
\end{abstract}

Keywords: Cinema. Literature. Time.

Pretendo, com o desenvolvimento deste trabalho, mostrar como o fluxo de consciência, que consiste em mostrar a continuidade de acontecimentos tal como ocorrem nos processos mentais, pelo qual o leitor ou espectador consegue visualizar os pensamentos das personagens, pode estruturar-se no cinema sem o recurso do flashback, flashforward e da narração em off. Para sua análise, o filme As Horas, dirigido por Stephen Daldry, estreado em 2003, e ganhador do Oscar de melhor atriz, foi analisado, em virtude de As Horas ser um bom exemplo do ponto a que chegou a representação do universo subjetivo nas realizações cinematográficas. O filme é uma adaptação do romance As Horas, de Michael Cunningham, de 1998, que, por sua vez, foi claramente inspirado na obra Mrs. Dalloway, de Virginia Woolf, principalmente na técnica subjetiva, o fluxo de consciência. A obra Mrs. Dalloway é, portanto, um dos principais referenciais no desenvolvimento desse trabalho, justamente por ser estruturada a partir do fluxo de consciência, aspecto esse também central na obra que inspirou o filme.

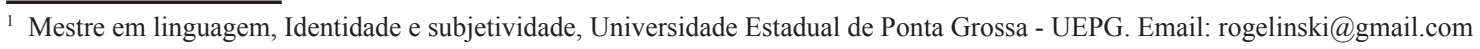


A escolha do filme As Horas, e não da adaptação cinematográfica de Mrs. Dalloway, deve-se ao fato de que em As Horas o diretor conseguiu fazer uma adaptação fundamentalmente introspectiva da narrativa do livro de Cunningham, procurando traduzir em imagens os processos que no romance de Woolf são trabalhados através da técnica literária do fluxo de consciência. Nesta perspectiva, o filme $A s$ Horas difere da adaptação Mrs. Dalloway, com direção de Marleen Gorris (1997), uma vez que este último permanece fiel ao romance de Woolf, tanto em relação à trama quanto ao uso de flashbacks e da voz em off, funcionando mais como uma ilustração do livro ao se apropriar dos eventos narrados, sem usar, portanto, um discurso que corresponda, em expressividade, ao de Virginia Woolf. Daldry, por sua vez, conseguiu, em seu filme, mostrar, através de imagens, como o fluxo de consciência ocorre, usando para isso um roteiro que se desenvolve muito próximo do estilo narrativo de Virginia Woolf.

Neste artigo, também serão levadas em consideração abordagens teóricas a respeito do tempo e do espaço, uma vez que o fluxo de consciência tem uma estreita relação com esses dois elementos, pois os pensamentos das personagens não apresentam uma cronologia exata, ao contrário, existe uma sucessão de reminiscências aparentemente vividas no presente, o que contribui para a quebra do limite espaço-temporal, ou, nas palavras de Gerard Genette (1989), ocorrem "distorções temporais" - uma mesma personagem pode invocar acontecimentos do passado, vivenciando-os no presente ou futuro.

\section{O tempo nas narrativas}

O tempo tem um papel de grande importância nas narrativas, pois em alguns casos, como nos romances de Virginia Woolf, ele é o próprio assunto. Mas defini-lo não é uma tarefa fácil, devido à sua pluralidade.

Tarefa que se torna ainda mais árdua no âmbito literário ou no âmbito cinematográfico. Entre os muitos filósofos que teceram inúmeras reflexões a respeito dessa questão, encontra-se Santo Agostinho:

O que é o tempo? Se ninguém me perguntar eu o sei; se eu quiser explicá-lo a quem me fizer essa pergunta, já não saberei dizê-lo. ${ }^{2}$

\footnotetext{
${ }^{2}$ AGOSTINHO, 1948, p. 346, apud NUNES, Benedito. O tempo na narrativa. São Paulo: Ática, 1988, p. 16.
}

Apesar de existirem muitas concepções a respeito do tempo, temos dificuldade em explicá-lo dificuldade essa já sentida por Santo Agostinho no longínquo século IV. Sabemos que o tempo se dá de forma sucessiva, que possui intervalos e duração. Mas na verdade não há um único conceito que possa dar conta da definição do que é o tempo. O senso comum define o tempo medido pelo relógio, pelo passar das horas, dos dias, semanas e dos anos. Mas quando se fala em tempo, ele é muito mais abrangente do que os processos cronológicos, com os quais estamos habituados. De forma mais aprofundada, há outras relações que alteram a concepção sobre o tempo. "Direta ou indiretamente as situações individuais, externas ou internas, bem como as experiências sociais ou culturais, interferem na concepção do tempo". (NUNES, 1988, p. 17).

Para Benedito Nunes (1988), em seu livro $O$ tempo da narrativa, há cinco processos temporais: tempo psicológico, tempo físico, tempo cronológico, tempo histórico e o tempo linguístico. Para efeito de análise, aprofundarei meus estudos nas situações relativas ao tempo psicológico, chamado também de duração interior, que, segundo Nunes, é classificado como a sucessão dos nossos estados internos, e não coincide com as medidas temporais objetivas, ou seja, com o tempo físico, que tem como caráter medidas precisas.

Uma hora pode parecer-nos tão curta quanto um minuto se a vivemos intensamente, e um minuto pode parecer tão longo quanto uma hora se nos entediamos. (NUNES, 1988, p.18).

O tempo psicológico compõe-se, portanto, de momentos imprecisos, no qual a percepção do presente se faz tanto em função do passado quanto em função do futuro, podendo variar conforme o indivíduo, uma vez que abrange sentimentos e lembranças.

Levando em consideração que minha análise abordará aspectos do romance Mrs. Dalloway, de Virginia Woolf, e do filme As Horas, faz-se necessário compreender como se processa o tempo nos textos narrativos e cinematográficos.

Segundo a conceituação de Christian Metz,

[...] a narração é, entre outras coisas, um sistema de transformações temporais. Em qualquer narração, o narrado é uma sequência mais ou menos 
cronológica de acontecimentos, no qual a instância-narradora reveste a forma de uma sequência de significantes que o usuário leva certo tempo para percorrer: tempo da leitura, para uma narração literária; tempo da projeção, para uma narração cinematográfica. (METZ, 1972, p. 32).

Para Nunes (1988), nos textos narrativos o tempo é apresentado através de acontecimentos e das suas relações com um tempo ficcional que consegue ligar momentos que o tempo real separa, bem como inverter a ordem desses momentos ou perturbar a distinção entre eles, uma vez que o tempo psicológico é capaz de mostrar, de maneira praticamente imperceptível, momentos vividos em diferentes épocas ou situações.

Como se sabe, a obra literária é composta por dois níveis: o da história e o do discurso. Enquanto aquele se refere ao conteúdo, o discurso refere-se à forma de expressão. Ou seja, a história refere-se aos acontecimentos, aos personagens e ao fato de evocar pontos de vista que se confundem com a vida real; por melhor dizer, a história evoca certa realidade. Mas essa mesma história não fica presa somente ao âmbito do livro, ela pode ser relatada a partir de um filme, ou oralmente, como é o caso das peças teatrais, por exemplo. E o discurso refere-se à maneira como o narrador relata a história, o que nos dá a configuração da narrativa como um todo. Assim não é a história por si só, mas a forma como o leitor fica conhecendo a história, através de sua leitura no espaço do texto. Conforme Gérard Genette (1989), na verdade o discurso não tem nenhuma pureza a preservar, pois é o modo "natural" da linguagem, acolhendo por definição todas as formas. Já a história, ao contrário, é um modo particular, definido por certo número de exclusões e de condições restritivas.

Tzvetan Todorov (1966) defende a ideia de que, na maior parte do tempo, o autor não tenta encontrar a sucessão natural dos acontecimentos porque se utiliza da deformação temporal para fins estéticos. Sendo assim, a deformação temporal seria a distinção do discurso para com a história.

O tempo do discurso é, num certo sentido, um tempo linear, enquanto que o tempo da história é pluridimensional. Na história muitos eventos podem desenrolar-se ao mesmo tempo. Mas o discurso deve obrigatoriamente colocá-los um em seguida ao outro; uma figura complexa se encontra projetada sobre uma linha reta. (TODOROV, 1971, p. 232).

O tempo na narrativa pode ser real ou imaginário, ou seja, quando breferência ao tempo da história, que pode ser imaginário, pois este permite retornos e antecipações, que podem acelerar ou retardar uma sucessão temporal. Já o tempo real refere-se ao discurso, que se mantém obrigatoriamente linear, pois obedece a estruturas do texto através de tempos verbais e linguísticos.

\section{Analepses e prolepses}

O recuo pela evocação de momentos anteriores como também o avanço pela antecipação de momentos posteriores aos que estão sendo narrados são denominados por Gérard Genette (1989), respectivamente, analepses e prolepses; e anacronia, no caso da duração interior, em que narradores se valem de formas analépticas e prolépticas, ou seja, retrospecção e prospecção. Isso porque há uma discordância entre a ordem da história e a ordem da narrativa.

A variação entre analepses e prolepses é frequente nos romances de fluxo de consciência; nesses romances o tempo aparece integrado à forma narrativa, ou seja, os romances de fluxo de consciência transformam o enredo a partir do momento em que a consciência assume o centro da narrativa. E a consciência como centro da ação faz com que nesses tipos de romances exista uma tendência para a análise profunda da vida psicológica das personagens, relacionando-as com acontecimentos exteriores. Virginia Woolf assim o faz em suas obras, pois penetra na intimidade das personagens que cria, narrando quase que imperceptivelmente as mudanças de pensamento e sua relação com o mundo exterior.

\section{O fluxo de consciência}

De maneira simplificada, o fluxo de consciência pode ser explicado a partir da nossa vida diária. É o que nós sempre fazemos quando remetemos um acontecimento ocorrido anteriormente ou posteriormente a outro. Tais momentos articulam-se num movimento contínuo de duração interior que relaciona 
ao mesmo tempo o passado, o presente e o futuro. É a liberdade do nosso $\mathrm{Eu}$, nossos pensamentos e nossas vivências, que nos conduzem para momentos de fluxo. O filósofo Bergson defende bem essa relação da duração e liberdade:

A duração completamente pura é a forma que a sucessão dos nossos estados de consciência toma quando nosso $\mathrm{Eu}$ se deixa viver, quando ele se abstém de estabelecer uma separação entre o estado presente e os anteriores. ${ }^{3}$

Mas, além do tempo, M. Forster (1974) defende o ponto de vista de que a intensidade dos acontecimentos também se torna relevante quando se trata de questões interiores. Porque não é somente o tempo que faz uma vivência tornar-se tão importante a fim de ser sempre rememorada, mas sim a sua intensidade. Nossas lembranças ou nosso olhar para o futuro dificilmente aparecem em nossa mente exatamente como um gráfico cronológico, uma sequência temporal. Haverá sempre uma seleção dos principais acontecimentos e com estes uma alteração na ordem sucessiva à medida que são pensados.

É isso que ocorre com Virginia Woolf, que altera os ponteiros do relógio ao escrever Mrs. Dalloway, tanto que a personagem Clarissa Dalloway pode estar ao mesmo tempo costurando um vestido, preparando uma festa, conversando com Peter Walsh, lembrando-se de Bourton e dos motivos pelos quais não estava casada com Peter. Clarissa não mostra as suas incertezas e temores. As outras personagens não conseguem ver o que se esconde atrás da face de Clarissa, ou seja, não há como saber o que se passa em sua mente, muitas são as suas lembranças, seus questionamentos e seus medos. A autora mergulha no psicológico de Clarissa para nos contar isso. Por exemplo, na conversa com Peter, há muita coisa que eles não falam um para o outro, mas o leitor fica sabendo que ela ainda se questiona por não ter casado com Peter.

[...] Porque não o convidaria para a sua festa? Perguntou ele.

Neste momento, pensou Clarissa, Peter está encantador! Perfeitamente encantador! Agora recordo como me parecia impossível resolver -

\footnotetext{
BERGSON, 1958, p. 74, apud NUNES, Benedito. O tempo na narrativa. São Paulo: Ática, 1988. p. 58
}

e por que o fiz, afinal? - não casar-me com ele, naquele terrível verão. (WOOLF, 1980. p. 43).

\section{Virginia Woolf}

Antes de falar sobre a organização poética no romance Mrs. Dalloway, é fundamental expor algumas características sobre a vida e obra de Virginia Woolf. Virginia Woolf nasceu em 1882 e cometeu suicídio em 1941. Devido aos princípios do pai, cresceu em um lar muito vitoriano e não pôde frequentar escolas tal como os irmãos. Portanto, era autodidata, porém não se orgulhava disso, era profundamente ressentida e politicamente argumentava contra os maus-tratos às mulheres no início do século XX. Sua carreira literária coincidiu com a Primeira Guerra Mundial, o que explica a relação constante com a realidade da época. Não que sua escrita tendesse apenas para o trágico, pelo contrário, a autora deixou-nos uma valiosa escrita de romances líricos e harmoniosos, enriquecendo-os quase sempre com metáforas e símbolos, considerando em suas obras temas como a dicotomia entre a vida e a morte, civilização e ignorância, loucura, política, frustrações e desencontros. Mas, na maioria de suas obras, Virginia Woolf privilegia o tempo como tema principal. Além de notarmos em sua obra a presença do tempo cronológico, percebemos em sua escrita a relação estritamente minuciosa com o tempo psicológico. Virginia Woolf ressalta a contradição da mente humana, capaz de registrar um fato e tão logo outro. Seria o que alguns filósofos chamam de simultaneidade e duração, pois muitas das ações em Mrs. Dalloway ocorrem no tempo passado, porém se conservam no presente.

\section{Mrs. Dalloway}

Woolf escreveu inúmeras obras, dentre as quais Mrs. Dalloway, publicada em 1925. O romance Mrs. Dalloway levanta questões quanto à efemeridade da vida, enfocando o tempo atrelado ao espaço. O início da narrativa é marcado pela frase: "Mrs. Dalloway disse que ela própria iria comprar as flores". (WOOLF, 1980, p. 1). Mrs. Dalloway ou Clarissa Dalloway é a esposa de um político, sai de casa a fim de providenciar os preparativos para uma 
festa à noite, na qual receberá velhos amigos. Ao longo do dia, Virginia Woolf revela um pouco sobre a protagonista e outras personagens importantes, tais como Peter Walsh, Septimus, Sally Seton e outros, através de pensamentos e lembranças, que sempre voltam ao passado e chegam até o presente. À medida que vamos lendo e sabendo um pouco mais sobre as personagens, tem-se a impressão de conhecê-las intimamente.

A escritora usa muito da sua experiência de vida e de seus problemas psicológicos na obra. Muitas das situações criadas em Mrs. Dalloway remetem à própria vida da autora. Tal como a personagem Clarissa Dalloway, Virginia Woolf também esteve inserida em uma sociedade burguesa, cheia de convenções e preconceitos, bem como vivenciou os horrores da Primeira Guerra Mundial, fortemente retratada em Mrs. Dalloway pela personagem Septimus. Através de Septimus e outras personagens, percebemos como a realidade ambiente é bem definida e como a consciência individual flui. Virginia Woolf, através de Clarissa Dalloway, dá voz aos problemas de sua época, mostrando uma sociedade que sofre com as consequências da Guerra, bem como aborda problemas de senso comum, como as relações afetivas, o cotidiano, os problemas econômicos e sociopolíticos.

\section{Síntese espaço-tempo}

Conforme Hilda Gouveia, "na tentativa de sugerir a duração, Virginia Woolf cria um clima ambíguo de subjetividade e objetividade através de imagens entrecruzadas, no qual sugere a união metafórica entre o tempo e o espaço, tal como uma cena cinematográfica" (GOUVEIA, 2007 p. 31). Pois Virginia transforma a ficção em acontecimentos progressivos assim como no cinema. A síntese entre o tempo e o espaço nas obras de Virginia ocorre porque ela usa de recursos cinematográficos que, segundo Gouveia, são comuns, como: close-up, fade in, fade out, flashback e flashforward, acrescentando que Virginia em sua grandiosa escrita nos revela um pensamento "enquanto pensado", pois as imagens que se criam a partir das leituras das obras de Virginia são imagens descontínuas voltadas mais para o interior dos personagens do que para o mundo exterior.
A não delimitação entre o passado, presente e futuro na narrativa tornou-se recurso literário de muitos escritores, como James Joyce, Marcel Proust e Virginia Woolf. Esta autora, em Mrs. Dalloway, através do uso frequente da transferência de consciência, bem como símbolos e metáforas, privilegia as técnicas cinematográficas, como mencionado acima. Principalmente porque em Mrs. Dalloway a construção da narrativa se dá a partir de analepses e prolepses, que respectivamente, como efeito cinematográfico, correspondem ao flashback e ao flashforward. Assim como na narrativa de Virginia Woolf, esses processos não ocorrem separadamente, mas sim de forma intercalada, tal como as cenas cinematográficas, o que de fato contribui para que não haja uma quebra da continuidade do discurso. Desta forma, a evocação ou antecipação dos acontecimentos desloca a mesma ação para o passado ou presente, tal como o cinema, que é capaz de interromper, retroceder ou adiantar uma ação. E ainda unir sequências temporais num só espaçotempo, entrelaçando as histórias e alternando os episódios.

Sendo assim, são válidas as palavras de Ismail Xavier ao dizer: "O cinema tanto pode voltar atrás (cut-back) a serviço das lembranças como pode cortar (cut-off) a serviço da sugestão" (XAVIER, 1983, p. 44). "Essa técnica das rápidas mudanças de cena, tão características do cinema, implica a existência de elementos sugestivos que, até certo ponto, unem as cenas separadas, assim como as afterimages ${ }^{4}$ unem quadros separados". (idem, p. 45). Então, nas cenas cinematográficas, o espectador tem a capacidade de integrar as cenas e relacioná-las, dando sentido ao filme.

\section{O tempo cronológico}

Em Mrs. Dalloway, além do tempo psicológico, o cronológico também está presente, sendo marcado pelas batidas do Big Ben. Ou seja, o poder do

\footnotetext{
${ }^{4}$ Afterimage: expressão inglesa que designa a imagem que permanece como conteúdo da percepção mesmo depois de o estímulo haver sido retirado. Caso típico é o da projeção cinematográfica, onde a sucessão de quadros fixos separados por intervalos pretos é percebida como evolução contínua, sem interrupção, de uma única imagem em movimento; remetemos à percepção de uma imagem até que a outra, que a substitui, vem compor novo estímulo. Se estas duas imagens contíguas correspondem a dois momentos bastante próximos de um movimento previamente registrado, havendo entre elas uma pequena diferença, teremos a ilusão de continuidade na projeção.
} 
tempo também é enfatizado através do som do relógio que, conforme Gouveia indica, é a metamorfose e a multiplicidade psicológica dos indivíduos, ou seja, simultaneamente registra a cronologia regular e o poder da duração interior que promove a união dos instantes isolados.

A batida do Big Ben, marcando a meia hora, ressoou entre ambos com extraordinário vigor, como se um homem jovem, forte, indiferente, descuidoso, estivesse a agitar a corda, de um lado para outro. (WOOLF, 1980, p. 49).

Eram precisamente doze horas; doze, pelo Big Ben; cujo sonido foi sendo arrastado para o norte de Londres; mesclando com o de outros relógios [...] Os pesados círculos dissolviam-se no ar. (idem, p. 92).

As eventuais batidas do Big Ben, constantemente citadas no romance, situam os leitores quanto à passagem do tempo, uma vez que o romance $M r s$. Dalloway se passa durante um dia em Londres, período esse em que Clarissa Dalloway prepara uma festa.

Integrada nas batidas do relógio que regulariza a cronologia dos incidentes, a festa é o mais poderoso símbolo do romance e, como celebração do moment essencial, reúne a história exterior e a vida intima de Clarissa. Aglutinada às diversas peculiaridades da realidade espacial, ela sugere também a duração absoluta, pois além de juntar vários estratos sociais, demonstra o milagre do presente e do passado conjugados na totalidade do tempo. (GOUVEIA, 2007, p. 73).

A cronologia regular foi igualmente muito bem retratada no filme As Horas, embora ocorra separadamente para cada personagem, pois as cenas são montadas num espaço de tempo muito grande entre elas, como nas cenas em que as três personagens principais acordam com o som do despertador. Logo mais, a personagem Vanessa chega adiantada para visitar Virginia, a exemplo de Louis que também visita Clarissa antes da festa. Assim como Clarissa que chega ao flat de Richard meia hora antes do horário marcado.

Genette (1989) afirma que a narrativa é uma sequência duas vezes temporal, porque existe o tempo do significado e o tempo do significante. Mas não é somente isso que explica as distorções temporais nas narrativas. Por exemplo, em Mrs. Dalloway, a vida de Clarissa é contada em um único dia, ou seja, momento em que prepara sua festa. Então, nas palavras de Metz, uma das funções da narrativa é cambiar um tempo por outro, por isso, "antes de tudo, a narrativa é um sistema de transformações temporais" (METZ, 1972, p. 27). E no cinema não é diferente, mas a vantagem é a presença da imagem que não transpõe apenas um tempo por outro, mas sim um espaço por outro. É exatamente por isso que a percepção das transposições temporais ou espaciais é tão complexa no cinema, pois não há uma informação do tempo e por vezes do próprio espaço ao longo das cenas. Por exemplo, no filme As Horas temos a localização de três tempos e três espaços distintos logo no início do filme, mas ao longo do filme o espectador não é avisado da época e local e tampouco se a cena está no presente ou passado. Justamente porque há um entrelaçamento dos tempos e dos espaços no filme.

Percebe-se então que a partir do momento em que se evoca o tempo no romance ou cinema haverá relação do mesmo com o espaço. Por melhor dizer, em Mrs. Dalloway há uma síntese do espaçotempo. Tal como as imagens em As Horas, o espaço no romance está bem marcado. Um bom exemplo ocorre quando a protagonista Clarissa Dalloway passeia pelas ruas de Londres, pois aí temos toda a descrição desde o trânsito londrino até as sensações de Clarissa. Nesse momento a agitação exterior de Londres contrasta com o interior da personagem.

Nos olhos dos passantes, na sua pressa, no seu andar, na sua demora; no burburinho e vozearia; carros, autos, ônibus, caminhões, homens, sanduíches bamboleantes e tardos; charangas; realejos; na glória e no rumor e no estranho aerocanto de algum avião sobre a sua cabeça, estava tudo isto, que ela amava: a vida, Londres; aquele momento de junho. (WOOLF, 1980, p. 8)

Movimento é isso que vemos no cinema. O movimento da imagem cinematográfica não separa o espaço do tempo assim como no romance Mrs. Dalloway. Toda a agitação que Clarissa vê e sente é a agitação que nós leitores imaginamos ver. $\mathrm{O}$ efeito desta agitação deve-se ao uso frequente de imagens sonoras. Assim, no romance é como se ela estivesse redescobrindo a vida, e para nós a impressão de estarmos assistindo a uma cena. Uma cena cheia de 
descrições sensoriais da vida em Londres e do deslumbramento de Clarissa.

\section{O fluxo de consciência de Mrs. Dalloway no cinema}

Inspirado no romance Mrs. Dalloway, o filme As Horas, dirigido por Stephen Daldry (2003), é uma adaptação do romance As Horas, de Michael Cunningham. $\mathrm{O}$ filme apresenta uma narrativa não linear e mostra um dia marcante na vida de três mulheres cujas histórias estão inter-relacionadas. Assim como no romance de Woolf, o diretor optou pela consciência das personagens, para descrever o pensamento das personagens e suas ações diante do tempo e do espaço.

Em As Horas, o espaço mostra-se bem marcado, seja pelo passeio de Clarissa Vaughan até a floricultura, seja no espaço físico do interior das casas, que, segundo Daldry, foram elaboradas de acordo com a época, ou seja, através do espaço o diretor do filme procurou mostrar como era a vida e como as pessoas viviam nas décadas de 1920, 1950 e no século XXI, buscando enfatizar também a personalidade de cada personagem. Um bom exemplo no filme de como o espaço físico pode revelar características de uma determinada personagem é o ambiente de Richard, um tanto sombrio, marcado pela escuridão do elevador, pelo ar de desleixo do flat, que acaba revelando muito sobre sua personalidade difícil e mal-humorada.

Christian Metz (1972) afirma que no cinema, efetivamente, o espaço está sempre presente; inclusive na narração, já que a narração fílmica se realiza pela imagem. Assim temos no filme As Horas um espaço, a exemplo do romance Mrs. Dalloway, marcado por ações cotidianas, tais como a preparação da festa por Clarissa, a preparação do almoço por Nelly e do bolo de aniversário por Laura, e, principalmente, os pequenos gestos do cotidiano, pois no filme as cenas de acordar, lavar o rosto, arrumar o cabelo e comprar flores intercalam-se entre as três personagens principais, relacionando três momentos diferentes, com um grande intervalo de tempo. Isso mostra o poder que os filmes têm de apresentar a simultaneidade apenas com o uso de imagens, pois não há narração verbal ligando as ações. Então, nesse momento o tempo passa a ser o mesmo para as ações das diferentes mulheres. O tempo parece não ter mudado, embora os acontecimentos estejam ocorrendo em épocas diferentes.

Ainda que o cinema e a literatura tenham suas particularidades, isso não impede que eles sejam analisados paralelamente. Mas uma diferença sobressai na relação cinema e literatura: é a impressão da realidade que o espectador vive diante de um filme.

O romance é primeiro uma narrativa, na qual o romancista coloca-se entre o leitor e a realidade que lhe quer mostrar, enquanto que no cinema o espectador é colocado diretamente em face dos acontecimentos que se desenrolam na cena. (BOURNEUF; OUELLET, 1976, p. 30).

Ao mesmo tempo o espectador torna-se perceptivo e participativo dos acontecimentos. Para Metz, a realidade é mais perceptível diante de um filme exclusivamente pela imposição do movimento que acarreta ao mesmo tempo a realidade e a corporalidade dos objetos.

Diferentemente da obra Mrs. Dalloway, o filme As Horas inicia e encerra com a cena do suicídio de Virginia Woolf. Também encontramos essa cena, muito bem relatada, no livro As Horas e na biografia sobre Virginia Woolf de Quentim Bell, sobrinho de Virginia.

Na manhã de sexta-feira, 28 de março, um dia claro, luminoso e frio, Virginia foi como de costume ao seu estúdio no jardim. Lá, escreveu duas cartas, uma para Leonard e outra para Vanessa - as duas pessoas que mais amava. Nas duas cartas explicava que vinha ouvindo vozes e acreditava que nunca mais ficaria boa; não podia continuar estragando a vida de Leonard. Ela colocou o bilhete sobre a lareira da sala de estar, e cerca de $11 \mathrm{~h} 30$ esgueirou-se para fora, levando sua bengala de passeio; e atravessou os prados até o rio. Leonard acreditava que ela já havia feito uma tentativa para se afogar: assim, teria aprendido com o fracasso, e estava decidida a não falhar de novo. Deixando a bengala na margem, ela esforçou-se para pôr uma grande pedra no bolso do casaco. Depois, encaminhou-se para a morte, 'a única experiência', dissera um dia a Vita 'que nunca descreverei'. 5

\footnotetext{
Disponível em: <http://www.revistabula.com/material/virginia-woolftentou-curar-sua-loucura-pelo-suicidio/598>. Acesso em 01 jun. 2009.
} 
Após a cena do suicídio, o filme nos informa sobre as três personagens femininas que vivem em épocas diferentes: Virginia Woolf (Nicole Kidman), que sofre de distúrbios mentais, escreve Mrs. Dalloway. O ano é 1923, a cidade é Richmond, Inglaterra. Laura Brown (Julianne Moore), em Los Angeles, em 1951, é uma dona de casa grávida, mãe de Richard (Ed Harris) e casada com um excombatente da Segunda Guerra Mundial (John C. Reilly). Para escapar de sua perturbação cotidiana, Laura prende-se na leitura de Mrs. Dalloway. E Clarissa Vaughan (Meryl Streep) é uma editora que vive em Nova Yorque, no ano de 2001, e que, como Clarissa Dalloway, também prepara uma festa, mas para homenagear o amigo Richard. Do mesmo modo que no início do romance, Clarissa Vaughan também diz que vai comprar flores. É curioso observar no filme que o livro Mrs. Dalloway mostra-se como um elo entre as três histórias. Enquanto Virginia Woolf o escreve, Laura Brown o lê e Clarissa Vaughan o vivencia, sendo ela o estereótipo da Mrs. Dalloway moderna, tanto que no filme ela é casada com Sally Seton, e no romance apenas temos a lembrança da felicidade que sentiu ao ser beijada pela sua amiga Sally em uma época marcada pelas convenções sociais. Do mesmo modo que há no romance elementos - como as referências ao Big Ben - que fazem a ligação entre elementos díspares, dando certa ordem às inúmeras digressões e associações de ideias, o livro funciona no filme como esse elemento, transitando entre as três épocas.

Os vários eventos do filme são moldados através da alternância das cenas entre as três mulheres, causando certo suspense para o espectador, que obviamente busca encontrar a conexão entre elas. Assim, as imagens passam a funcionar além das impressões visuais à medida que passam a refletir os sentimentos e a própria mentalidade das personagens.

Isso não acontece só relativamente às imagens, pois também a trilha sonora do filme, através da música minimalista de Philip Glass, reforça a atmosfera repetitiva das personagens, dando à narrativa mais escala e amplitude, uma vez que participa no estabelecimento da conexão do inconsciente das três histórias. Além da relação psicológica, a música enfatiza a cronologia regular, ou seja, a relação das horas na vida das personagens.
O filme faz uma ponte para o passado e para o futuro, mas nossa mente consegue acompanhar as três histórias porque ao assistirmos conseguimos entrelaçar o passado e o futuro com o presente. Embora o espectador saiba que nas cenas iniciais do filme trata-se de espaços e tempos diferentes, ao longo do filme é quase impossível percebê-las como sucessivas, pois a impressão que temos é de estarmos nos três lugares ao mesmo tempo. O que diferencia as cenas que apresentam esses espaços e tempos diferentes é a mise-en-scène, ou seja, a direção do filme aproximou-se muito da realidade das diferentes épocas através dos cenários, figurinos e da fotografia. Como exemplo, podemos citar a casa dos Woolf no interior da Inglaterra, mostrando inclusive a tipografia que Leonard construiu para a edição dos livros de sua esposa, bem como os vestidos e a aparência de Virginia, um resgate do vestuário do início dos anos 1920; a rua onde Laura Brown mora, típica da calmaria de um subúrbio de Los Angeles; e, por fim, Clarissa Vaughan, em Nova Iorque, de jeans e óculos de sol, passeando pelo trânsito, símbolo dos tempos modernos. As três histórias intercalam-se através de cortes simples, não há um narrador informando verbalmente a que espaço e tempo elas pertencem. Vem daí a impressão de se viver uma história através de outra, "como se fossem três sons que se fundem num mesmo acorde no qual o elemento temporal deixa de existir, e uma mesma ação irradia em todas as direções" (XAVIER, 1983, p. 42).

Dessa maneira, conforme exemplifica Xavier, "quando uma personagem recorda o passado que pode ser inteiramente desconhecido do espectador, os acontecimentos anteriores não surgem na tela como um conjunto isolado de cenas, mas ligam-se à cena presente, mediante uma lenta transição" (idem, p. 38), facilitando a compreensão do espectador. Assim, podemos deduzir que ao universo subjetivo funde-se a expressão corporal das personagens. Tal exemplificação ajusta-se perfeitamente às personagens do filme As Horas (2003).

A câmera tem esse poder de nos mostrar a visão de uma determinada personagem, diretamente, através do ponto de vista ótico, ou indiretamente, quando se percebe que uma determinada cena, mesmo que mostrada objetivamente, é filtrada pela subjetividade da personagem. A câmera pode assim penetrar na imaginação de uma personagem, mas de 
forma diferenciada do romance. No livro, o recurso verbal nos leva a penetrar no íntimo das personagens, mas no cinema isso se dá também através da imagem e do seu movimento, uma vez que as imagens podem assumir um caráter tão subjetivo quanto um texto.

Aqui cabe ressaltar a cena de Laura Brown no quarto do hotel, lendo Mrs. Dalloway, e praticamente decidida a encontrar a morte. Lentamente, seu quarto começa a ser invadido pela água, que ameaçadoramente começa a subir, numa situação quase surreal, que expressa o desespero que a domina e a iminência da morte. Considero essa cena a mais subjetiva de todo o filme, e é um exemplo do que foi afirmado acima. Embora não tenhamos o ponto de vista ótico de Laura, é através da subjetividade dessa personagem que a cena é filtrada - é a angústia dela que é expressa. A água que invade o quarto faz uma ponte com a cena da morte de Virginia Woolf. A primeira impressão do espectador pode ser de estranhamento - é óbvio que não é comum um rio invadir quartos de hotéis. Mas, nesse momento, estamos na consciência de Laura e, num processo semelhante ao fluxo de consciência literário, a associação com a cena da morte de Woolf é imediata.

Outra cena que alude à subjetividade de Laura Brown ocorre quando ela está no banheiro em estado de desespero, procurando responder, com naturalidade, como se nada estivesse acontecendo, ao esposo que se encontra no quarto. Muitos acontecimentos que antecedem este momento, como a conversa com Kitty e a sua ida ao hotel, explicam sua angústia. Essa cena no banheiro, segundo o diretor Stephen Daldry, não se consegue expor no papel, pois requer que a atriz mostre a habilidade de Laura fazer sua voz soar perfeitamente normal, enquanto ela está desesperada. Parece que o espectador penetra em sua mente e participa de toda a sua inquietação. E seu esposo não percebe que interiormente ela passa por um momento de grande agitação. E, logo depois, a cena termina no momento em que Laura aceita ir para a cama, o que, subjetivamente, mostra que ela escolheu abandonar sua família. Claro que não podemos ver isso de forma clara no filme, pois não há narração verbal que nos conte isso. Mas, como atesta o diretor Daldry (2003), esta cena, analisada de forma subjetiva, mostra a confusão interior de Laura e sua decisão de partir, o que pode ser explicado pela tomada do menino em seu quarto, deitado na cama e ouvindo a conversa dos pais, que, como demonstra em cenas anteriores, sente e parece prever que isso irá acontecer.

Outra cena em que a subjetividade é expressa é a que mostra Virginia Woolf participando do funeral de um pássaro em seu jardim. Nós, como espectadores, voltamos nossa atenção para o close-up do rosto de Virginia e do pássaro, e, ao mesmo tempo, como se as ações estivessem ocorrendo no mesmo período, temos o close-up do rosto de Laura contrastando com a cena de Virginia e do pássaro no jardim. E associamos a morte do pássaro, assim como Virginia o faz, com a morte da personagem do livro Mrs. Dalloway. Nesse momento pensamos: Laura Brown cometerá suicídio no quarto do hotel. No entanto, Virginia opta por não matar sua heroína, mas garante que alguém precisa morrer. E nesse momento é como se ela fosse a narradora do filme, ela é quem irá decidir qual personagem morrerá, o que leva o espectador a ficar apreensivo quanto à decisão de Virginia. É como se estivéssemos em sua mente.

No entanto, o close-up no filmeé mais instigante quando focaliza Laura Brown, técnica esta utilizada devido ao silêncio da personagem, pois ela não fala de seus sentimentos, e o espectador toma ciência de suas angústias através do seu comportamento, seus olhares, lágrimas, dificuldade quanto à preparação do bolo de aniversário para o esposo e de optar por abandonar a família ou cometer o suicídio.

Ficamos sabendo o que aconteceu com ela e a família somente no final do filme, com a morte de Richard, embora haja no filme uma cena reveladora antes do seu término, através do único flashback, quando Richard lembra-se de Laura Brown. Essa reminiscência de Richard quando criança leva o espectador a concluir que Richard e o filho abandonado por Laura Brown são a mesma pessoa.

Mas é somente na última cena que a personagem Laura Brown fala dos motivos que a deixaram em dúvida entre a morte e o abandono da família. Só então o espectador fica sabendo que a mãe de Richard o abandonou, "escolheu a vida em vez da morte". Clarissa Vaughan ao ouvi-la não demonstra odiá-la por isso, ao contrário, percebemos uma identificação entre ambas. Clarissa passa a considerar a importância de se estar viva e aproveitar todo o tempo, passa a valorizar a vida. A cena é comovente e parece insinuar que Laura Brown não é tão monstruosa quanto Julia 
afirma. A verdade é que o filme faz isso com quem assiste a ele, cria certa simpatia para com a cena, uma vez que todos merecem o direito de escolher o destino que desejam. É a sutileza da câmera que pode despertar na mente do espectador as particularidades de muitos comportamentos e emoções, a ponto de relacionarmos a dor, a angústia e o sofrimento de Laura Brown com os de Clarissa Vaughan.

Em As Horas constantemente o espectador é lembrado que as personagens sofrem com as lembranças do passado e vivem de forma conflitante diante da percepção do tempo. Richard sofre com a sensação de ser um escritor fracassado, bem como com as lembranças do seu passado, época de sua infância na qual fora abandonado pela mãe, Laura Brown. Esta sofre por não conseguir inserirse na vida familiar a que foi submetida e Clarissa Vaughan tem angústias vindas das lembranças de sua juventude e de sua relação com o amigo Richard. Essa relação lhe custou uma vida presa aos cuidados para com o amigo aidético, e Virginia vive uma vida que segundo ela lhe foi roubada, como demonstra a cena na estação de trem, uma vez que ela foi tirada de Londres para fazer seu tratamento médico, pois ouvia vozes e sofria de fortes dores de cabeça. Mas, para ela, a vida longe de Londres havia lhe tirado a inspiração e a vontade de viver, e como ser humano tinha o direito de viver no local de que gostava. Nessa cena Virginia convence Leonard que o melhor para ela é voltar a morar em Londres.

Como podemos notar no filme, ao mesmo tempo em que ele parece ser confuso, pela forma complexa como entrelaça as histórias e o mundo subjetivo de suas personagens, é por outro lado facilmente comparável com as nossas ações diárias. Pois o filme focaliza suas ações justamente no cotidiano das três mulheres, assim como no espaço em que vivem, mostrando, como no romance Mrs. Dalloway, toda a vida de três mulheres em apenas um dia. E neste único dia passamos a conhecer seus hábitos, sua rotina, seus desejos e angústias a ponto de vivenciarmos o momento em que suas decisões tornaram-se relevantes para o resto de suas vidas.

Voltando à questão da complexidade do filme, não podemos deixar de mencionar a habilidade de se elaborar um roteiro mediado pelo fluxo de consciência sem recorrer aos efeitos do flashback, do flashforward e tampouco das vozes em off. Por exemplo, no romance Mrs. Dalloway o que se passa na mente das personagens é internalizado pelos leitores através das reminiscências das personagens, entramos em suas mentes, a ponto de visitarmos seu passado e voltarmos para o presente, bem como podemos perceber seus pensamentos enquanto pensados, os quais funcionam como voz interior. Esses mesmos recursos também são utilizados em abundância no filme Mrs Dalloway, dirigido por Marleen Gorris (1997), através do flashback, que mostra as lembranças das personagens contrapondo através das cenas os acontecimentos do presente com o passado. No filme, assim co00mo na obra Mrs. Dalloway, Clarissa, ao sair de casa diz: "Que frêmito, Que mergulho!” (WOOLF, 1980, p.1), e logo depois se tem uma reminiscência, um flashback de quando ela tinha dezoito anos em Bourton. O outro recurso é a narração ou a voz em off, que expressa os pensamentos das personagens.

Percebe-se então, que num filme é comum a voz interior ser identificada com a narração em off, uma vez que o espectador não consegue ter o mesmo ponto de vista do leitor, que quando lê um livro tem a facilidade de penetrar na mente das personagens. Ao filme cabe a sugestão do espectador, que é movida pelas ações das personagens. E isso o livro não pode nos proporcionar, por exemplo, a ação de Clarissa separar as gemas de ovos no momento em que prepara o jantar da festa e conversa com Louis. A sonoridade que vem da ação dos ovos caindo na tigela, além de sugerir a cronologia regular, contrasta ao mesmo tempo com os seus pensamentos e com sua expressão corporal, revelando, a partir dessa cena, o seu grande conflito interior. A perturbação que está aprisionando-a passa a ser vivenciada pelo espectador, há uma conexão com o diálogo anterior de Richard e Clarissa, o qual nos leva a concluir que seu sofrimento parte de um relacionamento que não é presente e que ficou guardado na memória, nas lembranças de um verão.

Além de cenas como essa, existem no filme $A s$ Horas algumas relações interessantes quanto à narrativa. Por exemplo, a ligação entre as três histórias, que é mostrada nas primeiras cenas, e continua ao longo do filme, pode ser comparada a analepses e prolepses, que estão presentes no romance, já mencionado anteriormente - ambas correspondem respectivamente ao flashback e ao flashforward, uma 
vez que esses não são utilizados no filme. Sendo assim, a analepse, dentro da narrativa fílmica, pode ser definida pelo recuo de momentos anteriores, representada pela época de Virginia Woolf, em 1923, e a analepse seria o avanço pela antecipação de momentos posteriores, como a época de Clarissa Vaughan, em 2001, as quais se ligam à época de Laura Brown, 1951, que sugiro ser o ponto anacrônico da narrativa, ou seja, Laura Brown pode ser comparada ao momento presente, no qual vivencia subjetivamente através da leitura do livro Mrs. Dalloway momentos de antecipação e momentos de prospecção através da sua escolha em abandonar a família. O fluxo de consciência é, portanto, representado também pela oscilação das ações que se intercalam e ao mesmo tempo se entrelaçam na narrativa.

Como o flashback, o flashforward e a voz em off não aparecem no filme da mesma forma que no romance. O diretor optou por criar momentos que expressassem o interior das personagens, através de seus comportamentos e dos diálogos; e para isso a construção das imagens foi importantíssima, para que assumissem um caráter subjetivo. Tem-se como exemplo a cena quando Clarissa Vaughan chega ao flat de Richard para arrumá-lo para a festa e ele está totalmente perturbado. Em nenhum momento ele diz que irá cometer suicídio, mas nós, como Clarissa, percebemos que há algo de errado em suas atitudes: o movimento de abrir a janela, a ingestão de medicamentos misturados e principalmente a maneira de conversar com Clarissa como se esse fosse um momento normal, buscando entretê-la quando pede para que ela conte sobre seu dia. Ela parece relutar e não acreditar no que está vendo, mas sua expressão nos mostra toda a tensão da cena. Então, a exemplo do romance, quando Septimus se joga pela janela, temos um suicídio como símbolo dos efeitos não de uma guerra propriamente dita, mas de um outro tipo de guerra, que é a AIDS.

Através da cena do suicídio, outra relação pode ser feita considerando-se as palavras pronunciadas por Richard ao despedir-se de Clarissa: "Não creio que duas pessoas tenham sido mais felizes do que nós fomos" " ${ }^{6}$. São as mesmas palavras escritas na carta de Virginia Woolf para Leonard, momentos antes de ela cometer suicídio. As ações repetem-se,

DALDRY, Stephen. The hours, 2003 o que aconteceu em 1923, liga-se ao que está acontecendo em 2001, sendo, portanto, mais um elo entre as histórias.

A expressão de subjetividade desta cena está no fato de que Richard não conta que irá cometer suicídio, não em palavras, mas sua decisão já estava concluída na visita de Clarissa logo no início do filme, quando ela marca com Richard que passará em sua casa às 15:30 horas e ele diz que está ótimo. É como se Richard, pela sua expressão após o beijo de despedida em Clarissa, nos dissesse: "Já tomei minha decisão, vou acabar com o meu sofrimento e com o de Clarissa". Além da sua expressão, a mise-en-scène também contribui para que o espectador infira que haverá um desenlace trágico: o olhar de Clarissa, quando pergunta se ela ficaria zangada se ele morresse, bem como a aparência de Richard, o fato de ele não ter tomado os remédios e, principalmente a música que acompanha Clarissa ao sair do apartamento, indicando instabilidade. Logo, o espectador pode intuir que Richard não irá à festa, não tem motivos para comemorar e tampouco para continuar a viver, pois, como Richard afirma, ele não conseguiu ser um bom escritor, sentia-se insatisfeito com sua carreira e com a sua loucura e, tal como era Virginia, também vivia atormentado e ouvia vozes.

Richard deseja que Clarissa aproveite suas horas, seu tempo e que não se engane com festas porque, a exemplo de Peter Walsh no romance Mrs. Dalloway, também a acha trivial. "Ah! Mrs. Dalloway sempre dando festas para encobrir o silêncio" 7. Richard afirma que continua vivo só para satisfazê-la, pois se questiona sobre há quanto tempo Clarissa vai ao apartamento, deixando para um segundo plano a sua própria vida, a de Sally e de Julia. Mrs. Dalloway: "Quando eu morrer, vai ter de pensar em si mesma. Como vai ser então?" 8 .

E é exatamente o que ele faz, desiste da vida e espera que Clarissa continue a viver a sua. A morte é mais uma relação com o romance, a busca da liberdade e o sentido existencial, bastante enfatizado em Mrs. Dalloway através dos pensamentos da protagonista.

E, depois (sentira-o ainda naquela manhã), havia o terror; a acabrunhante incapacidade, pois nossos pais a puseram em nossas mãos, esta vida, para que

\footnotetext{
7 Idem.

8 Idem.
} 
a vivamos até o fim, para que andemos serenamente com ela; havia nas profundezas do seu coração um terrível medo. [...] Conseguiria escapar. Mas aquele jovem se havia suicidado. (WOOLF, 1980, p. 177).

Assim como acontece com a morte, há também a preocupação com o tempo cronológico, expressa pela inquietação de Richard - "Mas ainda preciso encarar as horas após a festa e as horas seguintes" ${ }^{9}$ - quando Clarissa lhe diz que a festa não tem importância. E de fato a festa perde a razão, e a metáfora do silêncio feita por Richard, revela-se porque, segundo ele, existem outras preocupações maiores do que a simples preocupação em organizar uma festa. Não é a festa que vai suprir a evasão de Richard. E é isso que faz de Clarissa um ser banal, o fato de ela ter dificuldade para compreender a passagem do tempo, tudo é diferente, nada será como um verão que passou com Richard.

Mas Clarissa mostra-se compreensiva nas últimas cenas do filme, enquanto conversa com Laura e passa a encarar o seu tempo de outra maneira, pois é possível amar a vida independentemente de se estar vivendo um bom ou um mau momento. Essa cena pode ser associada aos pensamentos de Virginia Woolf, quando ela fala para Leonard que algumas pessoas morrem para que outras passem a valorizar a própria vida. Inconscientemente, a partir da morte de Richard é isso que Clarissa faz, ela aceita sua vida. Ou nas palavras de Clarissa Vaughan, do livro As Horas:

Há apenas uma consolação: uma hora aqui ou ali em que as nossas vidas parecem, contra todas as probabilidades e expectativas, abrir-se de repente e dar-nos tudo quanto jamais imaginamos, embora todos, exceto as crianças (e talvez até elas), saibamos que a estas horas se seguirão inevitavelmente outras, muito mais negras e mais difíceis. Mesmo assim, adoramos a cidade, a manhã, mesmo assim desejamos, acima de tudo, mais. (CUNNINGHAM, 2003, p. 228).

E é isso que todas as personagens fazem, enca-ram as horas, embora a retomada da cena do rio mostre que a escolha de Virginia foi igual à de Richard. Essa última cena do filme é seguida em voice-off, pelo pensamento da personagem e da

\footnotetext{
Idem
}

música de Philip Glass, enquanto a cena de Virginia entrando no rio se repete e o filme termina:

Virginia: Dear, Leonard. To look life in the face. Always to look life in the face. And to know it for what it is. At last to know it, to love it for what it is. And then... To put it away. Leonard... Always the years between us. Always the years... Always ... The love. Always... The hours. ${ }^{10}$

E é essa fluidez, essa imprecisão, os anos... as horas..., que provocaram o desejo de realização desse trabalho. Nele procurou-se mostrar como a técnica subjetiva de Virginia Woolf, o fluxo de consciência, pode configurar-se no cinema sem o uso do flashback, flashforward e da voz em off. Embora a narrativa em As Horas não privilegie esses recursos, o diretor Stephen Daldry recorreu à mise-en-scène e aos comportamentos das personagens para demonstrar os pensamentos enquanto pensados.

Inicialmente, este trabalho abordou algumas definições a respeito do tempo e do espaço. Partiu-se de uma definição comum, a cronologia regular, para se chegar à concepção sobre o tempo psicológico e consequentemente ao fluxo de consciência. Para tanto, foram utilizados os conceitos de Benedito Nunes (1988), para mostrar que a subjetividade é composta por momentos imprecisos; e os conceitos de analepse e prolepse, para mostrar que uma narrativa, ao usar o tempo psicológico, estrutura-se através de retornos e antecipações, que podem acelerar ou retardar uma sucessão temporal, unindo sequências temporais num só espaço-tempo. Tal como ocorre em As Horas, uma síntese espaço-temporal, quando Daldry entrelaça a história da vida de três mulheres de épocas diferentes em único dia.

Além desses aspectos, foi necessário lançar mão de algumas abordagens cinematográficas de Christian Metz (1972) e Ismail Xavier (1983), para explicar como o espectador consegue fazer associações das cenas com o mundo subjetivo das personagens, uma vez que a imagem e o movimento podem assumir um caráter tão subjetivo quanto uma narração literária, embora esta difira da narração cinematográfica, que acaba proporcionando ao

\footnotetext{
10 Virginia: Querido, Leonard. Encarar a vida de frente. Encarar sempre a vida de frente. E conhecê-la como ela é. Enfim conhecê-la. Amá-la pelo que ela é. E depois... Descartá-la. Leonard... Sempre os anos entre nós. Sempre os anos... Sempre... O amor. Sempre... As horas. (In: DALDRY, Stephen. The hours, 2003, tradução nossa).
} 
espectador uma representação mais literal da realidade.

$\mathrm{Na}$ análise do filme As Horas, observou-se que o tratamento da subjetividade, através de técnicas narrativas cinematográficas, conseguiu se aproximar da linguagem literária introspectiva de Virginia Woolf, principalmente na utilização do recurso do fluxo de consciência, ou seja, o filme conseguiu mostrar ao espectador o que parecia ser impossível, o universo subjetivo de forma visível; a subjetividade que é somente internalizada pelos leitores de Mrs. Dalloway foi vivenciada pelos espectadores em As Horas. Desta forma, o filme ilustra, de forma convincente, como o fluxo de consciência ocorre, através de um discurso muito próximo ao de Virginia Woolf, ao mostrar a recorrência de momentos que estão minuciosamente inseridos no cotidiano das personagens, três mulheres separadas pelo tempo, cujas vidas estão intimamente interligadas pela obra Mrs. Dalloway.

\section{Referências}

AS HORAS. Direção: Stephen Daldry. São Paulo: Imagem Filmes, 2003.

BARTHES, Roland et al. Análise estrutural da narrativa. Tradução de Maria Zélia Pinto. Petrópolis, RJ : Vozes, 1971.

BELÉM, Euler de França. Virginia Woolf tentou curar sua loucura pelo suicídio, 2008. Disponível em: $<\mathrm{http} / / /$ www.revistabula.com/material/virginia-woolf-tentou-curarsua-loucura-pelo-suicidio/598>. Acesso em 01 jun. 2009.

BOURNEUF, Roland; OUELLET, Real. O universo do romance. Tradução de José Carlos Seabra Pereira. Coimbra: Livraria Almedina, 1976.

CUNNIGHAM. Michael. As horas. Tradução de Beth Viera. São Paulo: Companhia das Letras, 2003.

FORSTER, Eduard Morgan. Aspectos do romance. Tradução de Maria Helena Marins. Porto Alegre: Globo, 1974.

GENETTE, Gérard. Discurso da narrativa. Tradução de Leo Schlafman. Rio de Janeiro: José Olympio, 1989.

METZ, Christian. Significação no cinema. Tradução: Jean Claude Bernardet Perspectiva, São Paulo, 1972.

MRS. DALLOWAY. Direção: Marleen Gorris. Reino Unido, Estados Unidos, Holanda: First Look Pictures Releasing, 1997.

NUNES, Benedito. O tempo na narrativa. São Paulo: Ática, 1988.
OLIVEIRA, Hilda Gouveia. Imagens e criatividade no lirismo de Virgínia Woolf. Rio de Janeiro: Cátedra, 2007.

TODOROV, Tzvetan. As categorias da narrativa literária. In: BARTHES, Roland et al. Análise estrutural da narrativa. Tradução de Maria Zélia Pinto. Petrópolis, RJ : Vozes, 1971. p. 209-254.

WOOLF, Virginia. Mrs.Dalloway. - e - Book - Project Gutenberg. Australia, 2002. [on-line]. Disponível em: $<$ http://www.virginiawoolf.pro.br/cap1_escritora_vw.html >. Acesso em: 13 set. 2009.

WOOLF, Virginia. Mrs. Dalloway. Tradução de Mário Quintana. Rio de Janeiro: Nova Fronteira, 1980.

XAVIER, Ismail. A experiência do cinema: antologia. Rio de Janeiro: Graal, Embrafilmes, 1983. 